\title{
LEI GERAL DE PROTEÇÃO DE DADOS (LEI N 13.709/2018) E TERCEIRO SETOR: PRINCIPAIS DESAFIOS E ALTERNATIVAS RUMO À ADEQUAÇÃO
}

\author{
Maria da Conceição Lima Melo Rolim ${ }^{1}$ \\ Sandro Mansur Gibran²
}

\begin{abstract}
RESUMO
Objetivo do estudo: O objetivo do presente estudo é discorrer sobre a temática da LeiGeral de Proteção de Dados Pessoais (Lei $\mathrm{n}^{\circ}$ 13.709/2019) e discutir sobre sua aplicabilidade e efeitos no âmbito do Terceiro Setor. Metodologia/abordagem: O método de pesquisa escolhido foi a análise bibliográfica do tema atra vés de pesquisa por intermédio de livros, legislação e do Google Acadêmico, com a seleção de publicações como artigos e revistas da área. Originalidade/relevância: A discussão se insere dentro da matéria dos Direitos Fundamentais e Direito Civil, especificamente, dos Direitos da Personalidade. A relevância acadêmica está na novidade da LGPD no ordenamento jurídico brasileiro. Principais resultados: Como resultado, foi possível concluir pelo papel fundamental que boas práticas de governança podem exercer na formação de uma cultura de proteção de dados pessoa is nessas orga nizações. Contribuição teórica/metodológica. A pesquisa identificou os principais impactos que a nova sistemática de proteção à privacidade e de dados pessoais exercerá em relação às entidades do Terceiro Setor.
\end{abstract}

Palavras-chave: Lei Geral de Proteção de Dados Pessoais. Terceiro Setor. Adequação. Direitos da personalidade.

Submetido em: $12 / 10 / 2020$

Aprovado em: 01/03/2021

DOI: $\underline{\text { https://doi.org/10.37497/revcampojur.v9i1.723 }}$

1 Advogada, Mestranda em Direito Empresarial e Cidadania pelo Centro Universitário Curitiba- UNICURITIBA, Paraná (Brasil). Pós-graduanda pela AUDF/Brasília. Email:melorolimadv@hotmail.com ORCID 0000.0002.6463.3937.

2 Doutor em Direito Econômico e Socioambiental pela Pontifícia Universidade Católica do Paraná. Doc ente do Programa de Mestrado em Direito Empresarial e Cidadania pelo Centro Universitário Curitiba - UNICURITIBA, Paraná (Brasil). Email: sandro@rochaadvogados.com ORCID 0000.0003-2738-7199.

Campo Jurídico|Barreiras (BA) | v.9 |e723| p.01-19 |Janeiro-Junho|2021 


\title{
GENERAL LAW ON DATA PROTECTION (LAW N 13.709/2018) AND THIRD SECTOR: MAIN CHALLENGES AND ALTERNATIVES TOWARDS ADEQUACY
}

\begin{abstract}
Objective: The objective of this study is to discuss the theme of the General Law for the Protection of Personal Data (Law No. 13.709/2019) and discuss its applicability and effects within the Third Sector. Methodology/approach: The chosen research method was the bibliographic analysis of the theme through research through books, legislation and Academic Google, with the selection of publications such as articles and journals in the area. Originality/relevance: The discussion falls within the scope of Fundamental Rights and Civil Law, specifically, Personality Rights. The academic relevance lies in the LGPD's novelty in the Brazilian legal system. Results: As a result, it was possible to conclude for the fundamental role that good governance practices can play in the formation of a culture of personal data protection in these organizations. Theoretical/methodological contribution: The research identified the main impacts that the new system of protection of privacy and personaldata will exert in relation to Third Sector entities.
\end{abstract}

Keywords: General Personal Data Protection Law. Third sector. Adequacy. Personality rights.

\section{INTRODUÇÃO}

O presente artigo tem como objetivo discorrer sobre a temática da Lei Geral de Proteção de Dados Pessoais (Lei n ${ }^{\circ}$ 13.709/2018) e discutir sobre sua aplicabilidade e efeitos no âmbito do Terceiro Setor. Sendo assim, busca trabalhar e identificar os principais desafios e alternativas que as entidades desse setor se deparam no processo de adequação à LGPD.

A escolha desta temática se justifica pela relevância e pelos impactos que a nova sistemática de proteção à privacidade e de dados pessoais gerará em todos os setores da sociedade, considerando que a aplicabilidade da Lei Geral é extremamente ampla.

Especialmente, em relação às entidades do Terceiro Setor, que possuem inúmeras dificuldades de cunho técnico para se adaptar ao diploma, como será demonstrado.

A exposição será iniciada por uma abordagem acerca do panorama históricolegislativo dos temas "proteção de dados" e "privacidade". Será verificado, inicialmente, de que forma esses assuntos passaram a ser normatizados numa perspectiva internacional (europeia) e, posteriormente, será trabalhada a forma como foram evoluindo no ordenamento nacional.

Em seguida, realizar-se-á uma abordagem eminentemente teórica acerca dos principais pontos da Lei Geral de Proteção de Dados, para que se tenha uma compreensão preliminar mais completa de seus impactos e contribuições.

Ultrapassadas tais considerações, chega-se ao ponto principal do estudo, que, a partir das considerações acerca da LGPD, constatará quais são os principais desafios envolvidos na adequação das entidades do Terceiro Setor. Diante disso, também serão expostas algumas 
possibilidades para que o tema possa ser trabalhado de forma efetiva dentro dessas organizações.

Ao final, conclui-se pela necessidade da conformidade à Lei para que essas entidades não sofram sanções, sejam responsabilizadas ou, até mesmo, sofram repercussões em sua esfera econômica, considerando a influência que a adequação tem em relação às parcerias firmadas com o Terceiro Setor.

\section{PROCEDIMENTOS METODOLÓGICOS}

A pesquisa tem como procedimentos metodológicos a análise bibliográfica dos temas “Terceiro Setor" e "Lei Geral de Proteção de Dados" por meio de fontes secundárias, tais como: livros, legislação e o Google Acadêmico, em que foram selecionadas publicações como artigos e revistas da área. Para análise dos dados coletados na pesquisa, fora utilizada a técnica interpretativa.

\section{PROTEÇÃO DE DADOS E PRIVACIDADE: breve panorama histórico-legislativo}

\subsection{Experiência internacional}

Para que se possa compreender, efetivamente, de que forma o tema da proteção de dados e do direito à privacidade se inseriu no ordenamento jurídico nacional, é necessária uma investigação preliminar acerca da forma com que essa preocupação passou a ser trabalhada no contexto mundial.

Isso porque as primeiras experiências em busca de uma regularização da proteção de dados pessoais se deram, principalmente, nos países da Europa. Insta consignar que essa nova preocupação passou a ocorrer a partir da década de 1960, e que seu motivo inicial era proteger a privacidade das pessoas em detrimento do poder do Estado (OLIVEIRA; LOPES, 2019).

Ato contínuo, a proteção de dados em relação a terceiros também passou a ser o foco das legislações estrangeiras. A partir daí, tornou-se viável a identificação de princípios comuns entre os países, o que levou à promoção de iniciativas de cunho internacional, como a Convenção de Strasbourg e as Diretrizes da Organização para Cooperação e Desenvolvimento Econômico - OCDE (OLIVEIRA; LOPES, 2019).

O sistema europeu de proteção de dados, o chamado "General Data Protection Regulation" - GDPR ou "Regulamento Geral sobre a Proteção de Dados" - RGPD, entrou em vigor em maio de 2018 e é a principal fonte de inspiração da Lei Geral de Proteção de Dados -

Campo Jurídico|Barreiras (BA) | v.9 |e723| p.01-19 |Janeiro-Junho|2021 
LGPD brasileira. Ele derivou das diretivas 95/46/CE e 2002/58/CE e foi efetivamente editado no Regulamento EU 2016/2019 (OLIVEIRA; LOPES, 2019).

Trata-se de um sistema "coeso, pois organizado a partir das diretivas editadas pelo Parlamento do Conselho Europeu e, embora cada estado-membro tenha legislado sobre a matéria, inclusive por experiência da própria normativa, manteve-se o núcleo de proteção" (OLIVEIRA; LOPES apud DONEDA, 2019, p. 26).

Desse modo, pode-se dizer que modelo europeu vem servindo, atualmente, de norte para os países que buscam essa aprimoração legal, inclusive para o Brasil.

Insta ressaltar, no entanto, que a influência que o GDPR passou a exercer sobre outros países também se deu em virtude da necessidade de adequação, principalmente por parte de empresas que atuam no mercado internacional.

Isso porque estar adequado significa estar protegido das sanções que podem possivelmente ser aplicadas em virtude de uma atuação em desconformidade com o disposto no Regulamento Geral.

Tanto é assim que se fala, inclusive, em vantagens competitivas para atuação no mercado por parte de empresas que cumprem com os ditames desta nova sistemática.

Conforme será trabalhado adiante, de forma similar ao ocorrido na Europa, já existiam no Brasil diversas normas esparsas de proteção à privacidade e aos dados pessoais previamente ao aparecimento da LGPD.

Essas previsões, outrossim, não tratavam de forma específica sobre o assunto e basicamente traziam princípios que, posteriormente, foram incorporados à Lei Geral.

Assim, não há como negar que o modelo brasileiro foi diretamente inspirado pelo GDPR europeu, que realizou uma verdadeira sistematização na seara da proteção de dados.

\subsection{Experiência nacional e surgimento da Lei Geral de Proteção de Dados (Lei $\mathbf{n}^{o}$ 13.709/2018)}

No Brasil, anteriormente ao diploma unificador da proteção de dados pessoais, podese afirmar que já existia uma preocupação com a questão da privacidade de um modo mais geral, consoante previsão do artigo $5^{\circ}$, incisos X e XII da Constituição Federal:

Art. $5^{\circ}$ Todos são iguais perante a lei, sem distinção de qualquer natureza, ga rantindose a os brasileiros e aos estrangeiros residentes no País a inviolabilidade do direito à vida, à liberdade, à igualda de, à segurança e à proprieda de, nos termos seguintes:

X - são invioláveis a intimidade, a vida privada, a honra e a imagem das pessoas, assegurado o direito a indenização pelo dano material ou moral decorrente de sua violação; 
XII - é inviolável o sigilo da correspondência e das comunicações telegráficas, de dados e das comunicações telefônicas, salvo, no último caso, por ordem judicial, nas hipóteses e na forma que a lei estabelecer para fins de investigação criminal ou instrução processual penal; (BRASIL, 1988)

Em comento ao referido dispositivo constitucional, SCHREIBER (2018) defende que o direito à privacidade evoluiu de tal forma que, atualmente, se mostra especialmente necessária a sua proteção, diante constante vigilância e captação de dados a que todos estão sujeitos. Sua trajetória, portanto, acabou por superar a antiga concepção ligada unicamente ao contexto da moradia ou "vida privada".

Trata-se, por essa razão, de um conceito que abarca a "faculdade de exercer controle sobre o uso, a circulação e o armazenamento dos próprios dados pessoais" (SCHREIBER apud DONEDA, 2018, p. 170). Para além da intimidade, há, hoje, uma compreensão bem mais ampla da privacidade, que compreende o extenso mundo dos dados pessoais (normalmente, a esfera virtual).

Outro dispositivo constitucional relevante à temática de proteção de dados pessoais é o que prevê a possibilidade de concessão de Habeas Data (artigo 50, inciso LXXII, alínea "a") "para assegurar o conhecimento de informações relativas à pessoa do impetrante, constantes de registros ou bancos de dados de entidades governamentais ou de caráter público;" (BRASIL, 1988). Este remédio, por sua vez, está previsto na Lei $n^{\circ} 9.507 / 97$.

Também vale destacar a importância da Lei de Arquivos Públicos (Lei no 8.159/1991) para garantir o acesso do particular à informação. Nesse sentido:

\begin{abstract}
A Lei de Arquivos Públicos consa gra o direito do cidadão de acesso à informação de seu interesse particular ou de interesse público, assim como a proteção do sigilo, da intimida de e da vida privada sob pena de responsabilida de civil, penale administra tiva logo nos primeiros artigos. Não obstante os dispositivos sobre acesso e sigilo de documentos públicos estarem revogados pela Lei 12.572/2011 (Lei de Acesso à Informação), a rquivos cuja divulgação violasse a intimidade ou a vida privada, assim como ameaçasse a segurança da sociedade, eram considerados sigilosos e, portanto, submetidos a regras especiais previstas nos parágrafos do art. 23. (OLIVEIRA; LOPES, 2019, p. 27)
\end{abstract}

E, ainda, da Lei de Acesso à Informação (Lei n $12.527 / 2011)$ na proteção de dados pessoais:

A Lei de Acesso à Informação (Lei 12.527/2011) tem por objetivo assegurar o direito fundamental encampado no inciso XXXIII do art. $5^{\circ}$ da Constituição. Sua contribuição para a proteção dos dados pessoais, a lém do reforço ao equilíbrio entre a cesso, qua lida de da informa ção, proteção à priva cida de e sigilo, é a diversificação de categorias - ultrassecreta, secreta e reservada -, a lém do detalhamento dos critérios para classificação das informações. A lei dedicou, ainda, uma seção especial para tratar das informações privadas, conferindo a elas um tempo de sigilo máximo de 100 anos, que é bastante superior às demais categorias. Ta mbém estabeleceu como regra a exigência do consentimento para sua divulgação que só pode ser afa stada em ca sos 
específicos. O uso indevido das informações privadas acarreta a responsabilidade civil, nos termos dessa lei. (OLIVEIRA; LOPES, 2019, p. 27)

No que tange às normas de direito privado, a privacidade já era trabalhad a, de forma expressa, no Código Civil, vide artigos 12 e 21, dentro do capítulo destinado à proteção dos direitos da personalidade:

Art. 12. Pode-se exigir que cesse a ameaça, ou a lesão, a direito da personalidade, e reclamar perdas e danos, sem prejuízo de outras sanções previstas em lei. Pará grafo único. Em se tratando de morto, terá legitimação para requerer a medida prevista neste artigo o cônjuge sobrevivente, ou qualquer parente em linha reta, ou colateral até o quarto grau. (BRASIL, 2002)

Art. 21. A vida privada da pessoa naturalé inviolável, e o juiz, a requerimento do interessado, adotará as providências necessárias para impedir ou fazer cessar ato contrário a esta norma.(BRASIL, 2002)

Outrossim, ainda sob o aspecto privado, o Código de Defesa do Consumidor dispõe de forma bem detalhada sobre bancos de dados e cadastros de consumidores, previsão dos $\operatorname{artigos} 43$ e 44:

Art. $43 . \mathrm{O}$ consumidor, sem prejuízo do disposto no art. 86, terá acesso à s informações existentes em cadastros, fichas, registros e dados pessoais e de consumo arquivados sobre ele, bem como sobre as suas respectivas fontes. (BRASIL, 1990)

Art. 44. Os órgãos públicos de defesa do consumidor manterão cadastros a tualizados de reclamações fundamentadas contra fornecedores de produtos e serviços, devendo divulgá-lo pública e anualmente. A divulgação indicará se a reclamação foi atendida ou não pelo fornecedor. (BRASIL, 1990)

Os parágrafos do mencionado artigo 43 do diploma consumerista trazem diversas regras sobre o acesso desse banco de dados. Segundo a doutrina, tais dispositivos já continham diversos princípios que, somente com o advento da Lei Geral de Proteção de Dados, passaram a ter maior destaque: direito de acesso, qualidade dos dados, transparência, retificação e cancelamento (OLIVEIRA; LOPES, 2019).

De forma ainda mais específica, a Lei do Cadastro Positivo (Lei n $\left.{ }^{\circ} 12.414 / 2011\right)$, cujo objetivo é "disciplinar a formação e a consulta aos bancos de dados com informações de adimplemento, para a formação do histórico de crédito" (OLIVEIRA;LOPES, 2019, p. 28), tratou, além dos já citados princípios do CDC, a questão da responsabilidade objetiva e solidária. Sua principal inovação contudo, foi ao trabalhar a matéria das "informações sensíveis" (OLIVEIRA; LOPES, 2019).

Por fim, antecedendo ao advento da LGPD, cumpre sublinhar o papel fundamental exercido pelo Marco Civil da Internet (Lei n ${ }^{\circ} 12.965 / 2014$ ) à matéria da privacidade e proteção de dados pessoais. Isso porque essa legislação estabeleceu diversos direitos para os usuários, que também encontram guarida na atual Lei Geral: 
Entre os direitos do usuário, estão a inviolabilidade de sua vida privada - condição para o pleno exercício do direito de acesso -; o sigilo de suas comunicações; as informações claras, inclusive sobre proteçã o de dados pessoais e exclusão desses sob requerimento. $\mathrm{O}$ art.11 a ssegura a a plicação da legislação bra sileira para proteção dos dados quando ao menos uma das atividades de tratamento seja realizada no Brasil. (OLIVEIRA; LOPES, 2019,p. 28)

É possível observar, diante de todo o exposto, que o núcleo da LGPD, ou melhor, sua ideia central, já estava, de certa forma, presente no ordenamento jurídico nacional. Em síntese, nos dispositivos constitucionais, na Lei de Arquivos Públicos, na Lei de Acesso à Informação, nos direitos da personalidade do Código Civil, na proteção ao consumidor e na Lei do Cadastro Positivo.

Não obstante, a positivação, a reunião de princípios, os procedimentos, as sanções aplicáveis, enfim, toda a sistemática da proteção de dados certamente teve como marco principal a experiência estrangeira, que levou à edição do Regulamento Geral Brasileiro, a chamada Lei Geral de Proteção de Dados.

A seguir, serão trabalhados os principais aspectos referentes a este novel diploma legal que vem trazendo inúmeras preocupações e desafios a todos os setores da sociedade (público, privado e terceiro setor).

\section{LEI GERAL DE PROTEÇÃO DE DADOS (LEI No 13.709/2018) E TERCEIRO SETOR}

\subsection{Principais pontos da LGPD}

A Lei $\mathrm{n}^{\circ}$ 13.709/2018 surge no Brasil, com o objetivo de "proteger os direitos fundamentais de liberdade e de privacidade e o livre desenvolvimento da personalidade da pessoa natural", dispondo sobre o "tratamento de dados pessoais, inclusive nos meios digitais" (BRASIL, 2018), conforme seu artigo primeiro.

Nessa toada, esse mesmo texto normativo deixa clara a abrangência dos ditames da legislação tanto a pessoas físicas quanto a pessoas jurídicas de direito público ou privado, bem como ressalta a necessidade de observância em todo o território nacional (parágrafo único).

O escopo do presente artigo é analisar a aplicação da Lei Geral de Proteção de Dados no campo do Terceiro Setor. Assim, é possível identificar, desde já, que não há dúvidas acerca da aplicação da norma às entidades que dele fazem parte, independentemente da forma que são constituídas. Nesse sentido:

(...) as Organizações da Sociedade Civil que compõem o Terceiro Setor, inclusive as educacionais, independentemente da roupagem jurídica adotada (Associação, 
Fundação, Cooperativa Social ou Organização Religiosa), são significativas coletoras de dados pessoais, inclusive daqueles sensíveis e de crianças e adolescentes e, portanto, devem dar trata mento a dequado à queles (...) (FERNANDES, 2020, p. 1)

Os aspectos concernentes à aplicação da LGPD no Terceiro Setor serão aprofundados no tópico seguinte. Por ora, dar-se-á continuidade aos esclarecimentos sobre a Lei Geral para que se tenha uma ideia preliminar de seus objetivos, abrangência, aplicabilidade, princípios, bases legais, direitos dos titulares, responsabilidades e sanções.

A Lei Geral se aplica ao tratamento de dados pessoais de pessoa natural identificada ou identificável (art. $5^{\circ}$, inciso I). Define, por conseguinte, tratamento de dados como:

(...) toda operação realizada com dados pessoais, como as que se referem a coleta, produção, recepção, classificação, utilização, acesso, reprodução, transmissão, distribuição, processamento, a rquiva mento, armazenamento, eliminação, a va liação ou controle da informação, modificação, comunicação, transferência, difusão ou extração; (BRASIL, 2018)

Esse tratamento pode ser realizado em território nacional e ter como objetivo "a oferta ou o fornecimento de bens ou serviços ou o tratamento de dados de indivíduos localizados no território nacional" (BRASIL, 2018) ou os dados podem ser somente coletados em território nacional. Ou seja, há a possibilidade de aplicação da Lei fora do Brasil, vide artigo $3^{\circ}$ e incisos.

Todavia, existem situações em que os dispositivos da LGPD não são aplicáveis. Estas estão previstas no artigo $4^{\circ}$ :

Art. $4^{\circ}$ Esta Lei não se aplica a o tratamento de dados pessoais:

I - realizado por pessoa natural para fins exclusivamente particulares e não econômicos;

II - realizado para fins exclusivamente:

a) jornalístico e artísticos; ou

b) aca dêmicos, a plicando-se a esta hipótese os arts. $7^{\circ}$ e 11 desta Lei;

III - realizado para fins exclusivos de:

a) segurança pública;

b) defesa nacional;

c) segurança do Estado; ou

d) atividades de investigação e repressão de infrações penais; ou

IV - provenientes de fora do território nacional e que não sejam objeto de comunicação, uso compartilha do de dados com agentes de tratamento brasileiros ou objeto de transferência internacional de dados com outro país que não o de proveniência, desde que o país de proveniência proporcione grau de proteção de dados pessoais adequado ao previsto nesta Lei. (BRASIL, 2018)

Superadas as questões acerca da aplicabilidade da Lei Geral de Proteção de Dados, passa-se a um ponto de extrema relevância: seus princípios. Como visto anteriormente, algumas das principais normas de caráter principiológico abordadas pela LGPD já faziam parte do ordenamento.

Esses princípios irradiam sobre toda a Lei Geral, trazendo força aos seus ditames, pois estabelecem diretrizes que devem ser seguidos no tratamento de dados pessoais. São eles: boa- 
fé, finalidade, adequação, necessidade, livre acesso, qualidade dos dados, transparência, segurança, prevenção, não discriminação e responsabilização $\left(\operatorname{artigo~} 6^{\circ}\right.$ ).

Não se pode olvidar, ainda, que o artigo $2^{\circ}$ também possui caráter normativoprincipiológico, prevendo, por sua vez, os fundamentos da proteção de dados:

\footnotetext{
Art. $2^{\circ}$ A disciplina da proteção de dados pessoa is tem como fundamentos: $\mathrm{I}$ - $\mathrm{o}$ respeito à privacidade;

II - a autodeterminação informativa;

III - a liberdade de expressão, de informação, de comunicação e de opinião;

IV - a inviolabilidade da intimidade, da honra e da imagem;

V - o desenvolvimento econômico e tecnológico e a inovação;

VI - a livre iniciativa, a livre concorrência e a defesa do consumidor; e

VII - os direitos humanos, o livre desenvolvimento da personalidade, a dignidade e o exercício da cidadania pelas pessoas naturais. (BRASIL, 2018)
}

Quanto ao papel exercido pelos supracitados princípios, a doutrina destaca que "além do papel estrutural que a LGPD representa no chamado 'sistema brasileiro de proteção de dados', é interessante que os princípios indicados encontrem graus de concretude na própria lei” (OLIVEIRA; LOPES, 2019, p. 28).

As bases legais, sob outra perspectiva, representam os fundamentos ou as justificativas legais para os tratamentos de dados. Elas fazem parte do modelo de tratamento inaugurado pela Lei $^{\circ}$ 13.709/2018, que, conforme lecionam MEZENES e COLAÇO (2019, p. 78) se sustenta da seguinte forma:

O modelo de tratamento de dados instituído pela LGPD se ampara nas seguintes característica básicas: a ampliação do conceito de dado pessoal; o respeito à base legal; e o legítimo interesse como hipótese autoriza tiva e necessida de de rea lização de um teste de balanceamento de interesses.

De um modo geral, se trata das situações que devem ser observadas por parte dos sujeitos que realizam o tratamento para que este possa ser considerado lícito, adequado aos preceitos da Lei ora analisada. Nesse sentido dispõe o artigo $7^{\circ}$ da LGPD:

Art. $7^{\circ} \mathrm{O}$ tratamento de dados pessoais somente poderá ser realizado nas seguintes hipóteses:

I - mediante o fornecimento de consentimento pelo titular;

II - para o cumprimento de obrigação legal ou regula tória pelo controlador;

III - pela administração pública, para o tratamento e uso compartilhado de dados necessários à execução de políticas públicas previstas em leis e regulamentos ou respaldadas em contratos, convênios ou instrumentos congêneres, observadas as disposições do Capítulo IV desta Lei;

IV - para a realização de estudos por órgão de pesquisa, garantida, sempre que possível, a anonimização dos dados pessoais;

$\mathrm{V}$ - quando necessário para a execução de contra to ou de procedimentos prelim inares rela ciona dos a contra to do qual seja parte o titular, a pedido do titular dos dados; VI - para o exercício regular de direitos em processo judicial, administrativo ou arbitral, esse último nos termos da Lei ${ }^{\circ}$ 9.307, de 23 de setembro de 1996 (Lei de Arbitragem);

VII - para a Proteção da vida ou da incolumidade física do titular ou de terceiro;

VIII - para a tutela da saúde, exclusivamente, em procedimento realizado por profissionais de saúde, serviços de saúde ou autoridade sanitária; 
IX - quando necessário para atender aos interesses legítimos do controlador ou de terceiro, exceto no caso de prevalecerem direitos e liberdades fundamentais do titular que exijam a proteção dos dados pessoais; ou

$\mathrm{X}$ - para a proteção do crédito, inclusive quanto ao disposto na legislação pertinente. (BRASIL, 2018)

Dentre as referidas bases legais destacam-se, no presente estudo, a relevância do consentimento (inciso I) e o legítimo interesse (inciso IX). O consentimento significa a "manifestação livre, informada e inequívoca pela qual o titular concorda com o tratamento de seus dados pessoais para uma finalidade determinada;" (artigo $5^{\circ}$, inciso XII). Ele é concedido, comumente, na forma escrita e representa a concordância do titular.

Já o legítimo interesse é o extremo oposto, pois não necessita de qualquer tipo de autorização do titular para restar configurado. Ele estará presente nas situações do artigo 10 da LGPD (apoio e promoção das atividades do controlador; proteção do exercício regular dos direitos do controlador), mas não se limitam a elas. Por essa razão, essa base legal é extremamente subjetiva.

Ademais, considerando que as entidades do Terceiro Setor realizam, comumente, o tratamento de dados pessoais considerados como sensíveis, bem como de dados de crianças e adolescentes, é crucial mencionar de que forma a Lei Geral de Proteção de Dados trabalhou essas situações específicas.

Os dados sensíveis são aqueles que dizem respeito à origem (étnica ou racial), religião, opiniões de cunho político, filiação a sindicato ou organização religiosa, filosófica ou política, saúde, vida sexual, dados genéticos ou biométricos (vide artigo $5^{\circ}$, inciso II da Lei). Sendo assim, seu tratamento depende de consentimento específico por parte dotitular (artigo 11, inciso I).

O mesmo ocorre em relação aos dados de crianças e adolescentes. Segundo o caput artigo 14, ainda há um elemento subjetivo a ser observado: "o melhor interesse" do menor. O consentimento deverá ser concedido por, pelo menos, um dos pais ou pelo responsável legal da criança ou adolescente (parágrafo $1^{\circ}$ ).

A LGPD possui, ainda, um rol extenso de direitos do titular de dados. Inicialmente, no artigo 17, estabelece que "Toda pessoa natural tem assegurada a titularidade de seus dados pessoais e garantidos os direitos fund amentais de liberdade, de intimidade e de privacidade, nos termos desta Lei”.

Ato contínuo, elenca diversas modalidades de solicitações que o titular de dados pode exigir em face do controlador (principal responsável pelo tratamento de dados, conforme o 
artigo $5^{\circ}$, inciso IV da Lei): confirmação, acesso, correção, anonimização, portabilidade, eliminação, informação, revogação do consentimento.

A grande preocupação dos controladores, portanto, é demonstrar que o tratamento de dados pessoais está sendo realizado de forma lícita, bem como realizar um processo de ad equação para mapear e verificar de que forma esses dados estão sendo tratados para, então, responder às possíveis solicitações dos titulares.

A LGPD trata, em seção específica, da relevância das boas práticas e da Governança para que os responsáveis pelo tratamento de dados realizem tratamento lícito e, assim, possam demonstrar que estão cumprindo com os ditames da legislação. A adoção dessas práticas é fundamental para evitar posterior responsabilização cível e administrativa desses agentes.

Vale mencionar, desse modo, a previsão do artigo 50, parágrafo $2^{\circ}$, inciso I, que elenca os requisitos mínimos de um programa de governança em privacidade:

(...) I - implementar programa de governança em privacidade que, no mínimo:

a) demonstre o comprometimento do controlador em adotar processos e políticas internas que assegurem o cumprimento, de forma abrangente, de normas e boas práticas relativas à proteção de dados pessoais;

b) seja aplicável a todo o conjunto de dados pessoais que estejam sob seu controle, independentemente do modo como se realizou sua coleta;

c) seja adaptado à estrutura, à escala e ao volume de suas operações, bem como à sensibilidade dos dados tratados;

d) estabeleça política e salvaguardas a dequadas com base em processo de a valiação sistemática de impactos e riscos à privacidade;

e) tenha o objetivo de estabelecer relação de confiança com o titular, por meio de atuação transparente e que assegure mecanismos de participação do titular;

f) esteja integrado a sua estrutura geral de governança e estabeleça e aplique mecanismos de supervisão internos e externos;

g) conte com planos de resposta a incidentes e remediação; e

h) seja atualizado constantemente com base em informações obtidas a partir de monitora mento contínuo e a va liações periódicas; (BRASIL, 2018)

Todavia, caso sejam ocasionados danos em virtude de um tratamento ilícito, haverá a possibilidade de responsabilização solidária dos controladores e dos operadores (estes, por sua vez, operacionalizam o tratamento em nome dos controladores, estand o definid os no artigo $5^{\circ}$, inciso V). O tema da responsabilidade civil é trabalhado a partir do artigo $42 \mathrm{da}$ LGPD.

Por fim, mas não menos relevante, está a possibilidade de aplicação de sanções administrativas aos agentes de tratamento de dados que descumprirem às normas de Lei $\mathrm{n}^{\mathrm{o}}$ 13.709/2018. Essas sanções são aplicadas pela Agência Nacional de Proteção de Dados (ANPD) e variam da advertência à multa, cujo valor pode ser bem elevado. São elas:

Art. 52. Os agentes de tratamento de dados, em razão das infrações cometidas às normas previstas nesta Lei, ficam sujeitos às seguintes sanções administrativas a plicá veis pela autorida de nacional:

I - advertência, com indicação de prazo para a doção de medidas corretivas;

II - multa simples, de até $2 \%$ (dois por cento) do fatura mento da pessoa jurídica de direito privado, grupo ou conglomerado no Brasil no seu último exercício, excluídos 
os tributos, limitada, no total, a $\mathrm{R} \$ 50.000 .000,00$ (cinquenta milhões de reais) por infração;

III - multa diária, observado o limite totala que se refere o inciso II;

IV - publicização da infração após devidamente apurada e confirmada a sua ocorrência;

V - bloqueio dos dados pessoais a que se refere a infração a té a sua regularização;

VI - eliminação dos dados pessoais a que se refere a infração;

$X$ - suspensão parcialdo funcionamento do banco de dados a que se refere a infração pelo período máximo de 6 (seis) meses, prorrogável por igual período, até a regularização da ativida de de tratamento pelo controla dor;

XI - suspensão do exercício da atividade de tratamento dos dados pessoais a que se refere a infração pelo período máximo de 6 (seis) meses, prorrogável por igual período;

XII - proibição parcial ou total do exercício de atividades relacionadas a tratamento de dados. (BRASIL, 2018)

Percebe-se, portanto, que há muitas razões para que os agentes de tratamento de dados, inclusive as entidades de Terceiro Setor, estejam preocupados com o cumprimento da LGPD. Adiante serão expostos alguns dos principais desafios que este setor da sociedade vem se deparando e poderá se deparar no que se refere ao diploma de proteção de dados pessoais.

\subsection{Desafios e alternativas rumo à adequação no Terceiro Setor}

Apesar da ausência de previsão expressa na Lei ${ }^{\circ}$ 13.709/2018 acerca do tratamento dedados pessoais por parte das entidades que compõem o chamado Terceiro Setor, não há como negar a sua aplicabilidade nesse âmbito. A discussão vem, inclusive, despertando oportunidades de trabalho nesse setor:

O setor público e o privado, a ssim como o terceiro setor, estão em alta demanda por projetos de a dequação à LGPD e esse cenário tem gera do oportunidades de negócios para escritórios jurídicos e consultorias especializadas no tema. Dessa forma, o desenvolvimento e concepção de uma metodologia madura, a ssertiva e contendoboas práticas para implantação de projetos que exijam conhecimento sobre essa lei é um fator altamente requerido para propiciar uma agilidade no[sic.] diagnóstico e a obtenção de êxito nesse novo mercado, fazendo que os clientes que demandem essa atuação, mitiguem os riscos rapida mente (CELIDONIO; NEVES; DONÁ, 2020, p. 3)

As organizações do Terceiro Setor, por serem pessoas jurídicas de direito privado (sem finalidade lucrativa) que atuam na prestação de serviços de relevância pública, são responsáveis pelo tratamento de grande fluxo de dados pessoais, especialmente, de dados pessoais sensíveis.

Sobre essa categoria de dados, observa-se a seguinte interpretação:

Gustavo Tepedino e Chiara Spadaccini de Teffé (2019, p. 307), focando nessa categoria, afirmam: Essa categoria integra o chamado "núcleo duro" da privacidade, tendo em vista que, pelo tipo e natureza de informação que traz, ela apresenta dados cujo tratamento pode ensejar a discriminação de seu titular, devendo, por conseguinte, ser protegidos de forma mais rígida. Cuida-se de dados especialmente sensíveis do ponto de vista dos direitos e liberdades fundamentais, cujo contexto propicia riscos significativos para o titular. (LIMA; SÁ apud TEPEDINO; TEFFÉ, 2020, p. 11) 
Aqui reside primeiro desafio na ad equação à LGPD por parte dessas entidades, pois, como visto, dados pessoais sensíveis possuem uma proteção mais forte, já que o consentimento do titular desses dados deverá ser específico e destacado, para finalidade específica (ex vi do artigo 11, inciso I).

Para realizar a adequação, as organizações do Terceiro Setor deverão realizar uma revisão no processamento dessa modalidade de dados e preparar termo de consentimento, nos moldes da regra geral do inciso I do artigo supramencionado.

Não há a possibilidade de alegação de legítimo interesse para tratamento de dados sensíveis, porém, resta mencionar que a Lei prevê algumas hipóteses em que o consentimento não é exigido (artigo 11, inciso II).

Quando o titular de dados for pessoa com deficiência e não tiver o discernimento necessário para consentir, a única saída será a dispensa do consentimento com base no artigo $7^{\circ}$, incisos II a $\mathrm{X}$ (aqui incluso o legítimo interesse), ou, em se tratando de dados pessoais sensíveis, o enquadramento nas hipóteses do artigo 11, inciso II (LIMA; SÁ, 2020).

$\mathrm{Na}$ situação de existência de dados de crianças e adolescentes, repise-se que o tratamento dos dados deverá ser precedido de consentimento de um dos pais ou responsáveis, devendo o observar o melhor interesse do menor (red ação do artigo 14).

Outro desafio reside na possibilidade de transferência de dados entre entidades do Terceiro Setor e seus parceiros (públicos ou privados). Neste ponto, também se faz essencial uma gestão do consentimento, demonstrando, de forma transparente, a finalidade para que esse compartilhamento se faz necessário (MELO, OLIVEIRA e MOREIRA, 2020). Sendo assim:

\footnotetext{
As decisões tomadas neste momento histórico por empresas e pelo Poder Público, caso não levem em consideração as consequências desse uso para o porvir, podem gerar uma naturalização da perda das liberda des e do a gra vamento das desigualda des. Assim, a manutenção e ampliação do arcabouço de direitos fundamentais até aqui construído depende da capacidade de atuação da sociedade, principalmente, na disputa de narrativas em torno da interpretação de cada um deles. (FERNANDES, 2020, p. 3-4).
}

Essa gestão pode ocorrer por meio de alguns instrumentos, como Termos de Uso, Políticas de Privacidade e Termos de Consentimento. Trata-se de um ponto fundamental no movimento de adequação das entidades, pois há um verdadeiro “efeito dominó" quando se fala em compartilhamento de dados.

Isso que dizer que os parceiros das organizações sem fins lucrativos poderão exigir delas a demonstração do cumprimento à Lei Geral de Proteção de Dad os, para que, dessa forma, possa ocorrer o devido repasse de recursos e a concretização das parcerias (MELO, OLIVEIRA e MOREIRA, 2020). Afinal, ninguém quer ser responsabilizado pela má gestão de outrem. 
Ademais, como as organizações exercem o papel de controladoras, caso seja contratado um operador (prestador de serviços) para concretizar o tratamento, é de extrema importância a verificação da reputação desse prestador de serviço, bem como se ele está adequado às questões de privacidade; é necessário, ainda, estabelecer em contrato cláusulas expressas sobre sua responsabilidade, direitos e deveres (INSTITUTO PRO BONO, CASA HACKER e KLA, 2020).

Não se pode esquecer, ainda, que os operadores são terceiros e que receberão dados sob a forma de compartilhamento, por isso, a Lei exige que o titular tenha ciência dessa possibilidade, bem como das razões pelas quais o controlador o efetuará.

Em relação às parcerias firmadas com o poder público, pode-se dizer que o compartilhamento ocorre com o intuito de concretizar políticas públicas e que há um desafio em relação a garantir, ao mesmo tempo, a privacidade dos dados e a transparência (FERNANDES, 2020). Nesse sentido:

O grande desafio da Administração Pública será em relação a o compartilha mento dos dados pessoais sem comprometer a proteção e segurança das informações, desde a coleta a té a sua destruição, visto que a interoperabilidade é permitida, observados os pressupostos do atendimento de políticas públicas ou da prestação de serviços públicos. Note-se que o compartilhamento de dados pelo Poder Público a entidades priva da sé vedado, exceto nos ca sos de execução descentra liza da de ativida de pública para finalidade específica e determina da, nos ca sos em que os dados forem acessíveis publicamente, baseadas em contratos, convênios ou instrumentos congêneres ou na hipótese exclusiva de prevenir fraudes ou proteger a segurança do titular dos dados. (MAGACHO; TRENTO, 2021,p. 10)

Considera-se, ainda, que a LGPD impactará o Terceiro Setor no sentido de: ser necessário diagnosticar e adaptar as áreas de cada organização, principalmente dos setores que realizam captação, armazenamento e utilização de informações dos beneficiados e dos stakeholders, bem como na área de Recursos humanos; possibilitar-se o a melhoria dos Controles Internos dentro de cad a instituição; aumentar-se a proteção contra ataques de hackers (FERNANDES, 2020).

Diante disso, a melhor possibilidade para que o Terceiro Setor realize sua adequação aos termos do novo diploma é a promoção e aplicação de práticas de Governança: essa é a condição sine qua non para que se possa buscar a conformid ade ao sistema de proteção de dados pessoais. Contudo, na prática, não é tão simples. Existem diversos obstáculos que precisarão ser superados para que essas boas práticas sejam aplicadas. Assim:

A rapidez e a evolução digital globalizada elevaram os dados pessoais a uma verdadeira condição de commodities e com isso, trazem em si riscos inerentes a sua própria natureza. O estabelecimento do compliance e dos preceitos da LGPD são apenas vetores em prol da ética, integridade e proteção dos dados pessoais. A necessidade e urgência vão muito além das normas positivadas; significa envolver e 
assegurar o comprometimento dos a gentes públicos em sua essência. ((MAGACHO; TRENTO, 2021, p. 16)

Inicialmente, uma etapa preliminar de mapeamento dos dados que estão sendo tratados nas organizações deverá se dedicar a categorizar e eliminar dados desnecessários. Por óbvio, na maior parte das entidades devemexistir pilhas e pilhas de arquivos desatualizad os que devem ser eliminados. É crucial que sejam verificados os dados que continuam a ser armazenados na forma física.

Na parte virtual, algumas medidas de segurança podem ser tomad as com o objetivo de evitar vazamentos e tornar o armazenamento de dados (especialmente aqueles que possuem tratamento especial, como dados sensíveis e dados de crianças e adolescentes).

A Cartilha de "Boas práticas de proteção de dados (LGPD) para o terceiro setor" (INSTITUTO PRO BONO, CASA HACKER e KLA, 2020, p. 13-14) elenca alguns exemplos de medidas que, de um modo geral, podem ser aplicadas em relação ao tratamento de dados no Terceiro Setor:

\footnotetext{
Adoção de um programa de governança e privacidade;

Criação de uma equipe responsável pela Proteção de Dados Pessoais dentro da Orga nização e nomeação de um encarrega do de Proteção de Dados;

Adição dos princípios de Privacy by Design e Privacy by Default durante a execução das atividades de Tratamento de Dados Pessoas;

Criação de políticas de confidencia lidade com colabora dores;

Estabelecimento de medidas como criptografia; firewall; senhas fortes; bloqueio de transferência e impressão de documentos (...)
}

No mais, se a entidade possuir um site ou realizar coleta de dados pessoais por intermédio dessa página da web, recomenda-se a inclusão de uma Política de Privacidade, cujo conteúdo está previsto no artigo $9^{\circ}$ da LGPD. Nessa página também poderá ser disponibilizada informação acerca do Encarregado de Proteção de Dados (artigo 41, §1º).

Não obstante, não basta apenas prever boas práticas de proteção de dados pessoais e realizar a adequação formal. Um movimento de perpetuação deve ser buscado através do treinamento periódico de todos os setores das organizações, especialmente dos funcionários/voluntários que estejam envolvidos nas partes de maior risco de incidentes (setor de tecnologia e Recursos Humanos, por exemplo).

Destarte, é aconselhável que os colaboradores estejam conscientes a respeito da Política de Privacidade e da forma com que se deve lidar com incidentes de segurança, assim como com possíveis solicitações de titulares de dados. Uma recomendação de grande relevância 
é, também, a revisão dos contratos dos colaboradores, para que incluam cláusulas de confidencialidade e medidas disciplinares a serem adotadas em caso de descumprimento da LGPD (INSTITUTO PRO BONO, CASA HACKER e KLA, 2020).

Identificados os pontos desafiadores e as possibilidades para o Terceiro Setor, o próximo passo deve ser o desenvolvimento de uma cultura de proteção de dados nas organizações. É preciso informar e buscar informações sobre o assunto, para que, dessa forma, possam ser tomadas as devidas providências para prevenção de incidentes envolvendo privacidade e proteção de dados pessoais.

Segundo a pesquisa "LGPD e o Terceiro Setor", de Jérémie Dron, essas entidades já estão conscientes da necessidade de mudança: “69\% das organizações da sociedade civil (OSCs) já ouviu falar sobre Lei Geral de Proteção de Dados Pessoais (LGPD), mas ainda não se aprofund ou no tema" (GIFE, 2020, p. 1); em contrapartida, "91\% acred ita que o impacto da nova legislação será, ao menos, moderado para o terceiro setor” (GIFE, 2020, p. 1).

Ocorre que, segundo a mesma pesquisa, apenas 44\% "sempre pedem o consentimento formal dos titulares para usos dessas informações" (GIFE, 2020, p. 1), o que nos leva a concluir que o caminho para a formulação dessa cultura de proteção de dados ainda é longo. Por outro lado, o tempo é curto, visto que as sanções administrativas poderão começar a ser aplicadas a partir de agosto de 2021.

Por fim, a adequação é fundamental para que, acima de tudo, essas entidades possam continuar funcionando, pois, para além dos aspectos jurídicos, há o fator econômico, já que “instituições europeias que já com a GDPR em vigor, podem, por exemplo, decidir não aportar recursos a instituições brasileiras por ainda não contarem com processos adequados (...)" (GIFE, 2020, p. 2).

\section{CONSIDERAÇÕES FINAIS}

O presente estudo permitiu verificar que o ordenamento jurídico brasileiro vem evoluindo no que tange à temática da proteção da privacidade e do tratamento de dados pessoais. Vivenciam-se tempos em que as relações interpessoais, econômicas e até mesmo de caráter público dependem do compartilhamento de milhares de informações, todos os dias, a todo momento. Sendo assim, foi preciso estabelecer um sistema coeso de normas protetivas às pessoas naturais (titulares de dados), de inspiração no GDPR europeu.

Verificou-se, ainda, que tais normas possuem aplicabilidade em todos os setores da sociedade, inclusive em relação às entidades que compõem o chamado Terceiro Setor. Dessa 
forma, empresas, órgãos públicos, organizações da sociedade civil e até mesmo pessoas físicas que realizam tratamento de dados pessoais se deparam com a necessidade de realizar sua adequação à nova Lei Geral de Proteção de Dados Pessoais (Lei nº 13.709/2018).

As entidades do Terceiro Setor possuem, até agosto de 2021, o dever de promover uma verdadeira revolução na forma como vêm realizando o tratamento de dados pessoais. A Lei Geral de Proteção de Dados irá, certamente, forçar que essas organizações se modernizem, adotem sistemas mais tecnológicos e seguros. No entanto, a tarefa não será e não tem sido fácil. Em virtude do caráter sui generis das pessoas jurídicas que compõem o Terceiro Setor, puderam ser identificados alguns obstáculos nessa caminhada pela defesa da privacidade.

Apesar de todas essas dificuldades, constatou-se possibilidades para que tais organizações estejam em conformidade com a LGPD. Primeiramente, com a conscientização da necessidade de mudança, um movimento que já está em andamento em todo território nacional. Em seguida, com a aplicação de boas práticas de governança em todos os setores das entidades, especialmente com a promoção de palestras e treinamentos.

Ato contínuo, o Terceiro Setor deverá se livrar de dados desnecessários e realizar, com isso, uma filtragem do que está sendo tratado. Assim, poderá ser realizado o mapeamento de dados e instaladas medidas de segurança com o intuito de evitar incidentes. Também é muito importante a realização de um movimento de adequação dos contratos e das parcerias, bem como o desenvolvimento de políticas internas e externas de privacidade.

Na prática, essas medidas são fundamentais para que o Terceiro Setor possa continuar atuand o de forma adequada às determinações da LGPD, bem como para que não seja penalizado pelos próprios parceiros (doadores, pessoas jurídicas de direito público, empresas). O movimento de adequação vai muito além das consequências internas, pois pode impactar todos os sujeitos que estão envolvidos no compartilhamento de dados pessoais.

Daí a extrema relevância da temática para o referido setor, que deverá desenvolver uma cultura de proteção de dados e de respeito às boas práticas para que não sofra com sanções administrativas, responsabilizações perante o poder judiciário e, até mesmo, com a "quebra" de suas atividades pela ausência de parcerias. 


\section{REFERÊNCIAS}

BRASIL. Constituição (1988). Constituição da República Federativa do Brasil. Brasília: Senado Federal, $1988 . \quad$ Disponível em: <http://www.planalto.gov.br/ccivil_03/constituicao/constituicao.htm>. Acesso em: 22 nov. 2020.

BRASIL. Lei n ${ }^{\circ}$ 8.078, de 11 de setembro de 1990. Dispõe sobre a proteção do consumidor e dá outras providências. Brasília: Congresso Nacional, 1990. Disponível em: < http://www.planalto.gov.br/ccivil_03/leis/18078compilado.htm>. Acesso em: 22 nov. 2020.

BRASIL. Lei no 10.046, de 10 de janeiro de 2002. Institui o Código Civil. Brasília: Congresso Nacional, $2002 . \quad$ Disponível em: < http://www.planalto.gov.br/ccivil_03/leis/2002/L10406compilada.htm>. Acesso em: 22 nov. 2020.

BRASIL. Lei no 13.709, de 14 de agosto de 2018. Lei Geral de Proteção de Dados Pessoais (LGPD). Brasília: Congresso Nacional, 2018. Disponível em: < http://www.planalto.gov.br/ccivil_03/_ato2015-2018/2018/lei/L13709.htm>. Acesso em: 22 nov. 2020.

Boas Práticas de proteção de dados (LGPD) para o Terceiro Setor. Casa Hacker, instituto pro bono e KLA, 2020. Disponível em: < https://probono.org.br/acao/cartilha-protecao-de-dadoslgpd-para-o-terceiro-setor/>. Acesso em: 22 nov. 2020.

Como a Lei Geral de Proteção de Dados Pessoais irá impactar o terceiro setor. Gife, 2020. Disponível em: < https://gife.org.br/como-a-lei-geral-de-protecao-de-dados-pessoais-iraimpactar-o-terceiro-setor/>. Acesso em: 22 nov. 2020.

CELIDONIO, T.; NEVES, P.S.; DONÁ, C.M. Metodologia para mapeamento dos requisitos listados na LGPD (Lei Geral de Proteção de Dados do Brasil número 13.709/18) e sua adequação perante a lei em uma instituição financeira - Um estudo de caso. Revista Brazilian Journals of Business, Curitiba, v. 2, n. 4, p. 3626-3648 out. /dez. 2020. Disponível em: <https://www.brazilianjournals.com/index.php/BJB/article/view/18382>. Acesso em: 01 jul. 2021.

DONEDA, Danilo. Da privacidade à proteção de dados pessoais. Rio de Janeiro: Renovar, 2006.

FERNANDES, E. R. RESENHA À OBRA A LGPD E O NOVO MARCO NORMATIVO NO BRASIL, DE MULHOLLAND, CAITLIN (ORG;). PORTO ALEGRE: ARQUIPÉLAGO, 2020. Revista Brasileira de Direito Civil - RBDCivil, Belo Horizonte, v. 24, p. 263-266, abr./jun. 2020.2 Disponível em: <https://https://rbdcivil.ibdcivil.org.br/rbdc/article/download/571/371>. Acesso em: 01 jul. 2021.

FERnANDES, M. Lei Geral de Proteção de Dados - LGPD - No Terceiro Setor: Associações, fundações, cooperativas sociais e entidades religiosas. [s.l]: Meira Fernandes Gestão e Soluções para Instituições de Ensino, 2020. Disponível em: < Campo Jurídico|Barreiras (BA) | v.9 |e723| p.01-19 |Janeiro-Junho|2021 
https://www.meirafernandes.com.br/artigo/106/lei-geral-de-protecao-de-d ados-lgpd-noterceiro-setor-associacoes-fundacoes-cooperativas-sociais-e-entidades-religiosas $>$. Acesso em: 22 nov. 2020.

LIMA, T. M. M. De; SÁ, M. De F. F. De. As pessoas com deficiência no microssistema de proteção de dados pessoais. [s.l.]: Revista Duc In Altum Cadernos de Direito, vol. 12, $\mathrm{n}^{\mathrm{o}}$ 26, jan-abr. 2020. $\quad$ p. $27-55 . \quad$ Disponível em: https://faculdadedamas.edu.br/revistafd/index.php/cihjur/article/view/1219>. Acesso em: 22 nov. 2020.

MAGACHO, B. T. P. .; TRENTO , M. . LGPD e compliance na Administração Pública: O Brasil está preparado para um cenário em transformação contínua dando segurança aos dados da população? É possível mensurar os impactos das adequações necessárias no setor público?

Revista Brasileira de Pesquisas Jurídicas (Brazilian Journal of Law Research), Avaré: Eduvale, v. 2, n. 2, p. 7-26, 2021. Disponível em: <https://ojs.eduvaleavare.com.br/index.php/rbpj/article/view/30.>. Acesso em: 01 jul. 2021.

MELO, R.D.; OLIVEIRA, L.C. De; MOREIRA, G. A Lei Geral de Proteção de Dados e as entidades do terceiro setor. [s.1.]: Migalhas, 2020. Disponível em: < https://migalhas.uol.com.br/depeso/332683/a-lei-geral-de-protecao-de-dados-e-as-entidadesdo-terceiro-setor>. Acesso em: 22 nov. 2020.

MENEZES, J.B. De; COLAÇO, H. S. Quando a Lei Geral de Proteção de Dad os não se aplica?. In: TEPEDIDO, G.; FRAZÃO, A.; OLIVA, M. D. (Coord.). Lei Geral de Proteção de Dados Pessoais e suas repercussões no Direito Brasileiro. São Paulo: Thomas Reuters Brasil, 2019.

OLIVEIRA, M. A. B.; LOPES, I. M. P. Os princípios nortead ores da proteção de dados pessoais no Brasil e sua otimização pela Lei 13.709/2018. In: TEPEDIDO, G.; FRAZÃO, A.; OLIVA, M. D. (Coord.). Lei Geral de Proteção de Dados Pessoais e suas repercussões no Direito Brasileiro. São Paulo: Thomas Reuters Brasil, 2019.

SCHREIBER, A. [et al.]. Constituição Federal Comentada. Rio de Janeiro: Forense, 2018.

TEPEDINO, Gustavo; TEFFÉ, Chiara Spadaccini. Consentimento e proteção de dados pessoais na LGPD. In: TEPEDINO, Gustavo; FRAZÃO, Ana; OLIVA, Milena Donato (Coord.). Lei Geral de Proteção de Dados Pessoais e suas repercussões no direito brasileiro. São Paulo: Thomson Reuters (Revista dos Tribunais), 2019, p. 287-322. 